\title{
Impacts of work-family role conflict on job and life satisfaction: a comparative study among doctors, engineers and university teachers
}

\section{Tazrin Jahan Priyanka, Momotaj Akter Mily and Md. Asadujjaman Department of Industrial and Production Engineering, Rajshahi University of Engineering and Technology, Rajshahi, Bangladesh}

Mohammad Arani

Department of Systems Engineering, University of Arkansas at Little Rock, Little Rock, Arkansas, USA, and

Md. Mashum Billal

Department of Industrial and Production Engineering,

Rajshahi University of Engineering and Technology, Rajshahi, Bangladesh

\begin{abstract}
Purpose - This study was designed to investigate the impacts of work-family role conflict on job and life satisfaction among three major professionals: doctors, engineers and university teachers. Data were collected through a face to face survey on 60 doctors, 60 engineers and 60 university teachers of different public and private institutes of Bangladesh.

Design/methodology/approach - Conducted data analysis were statistical analysis of questionnaires (mean, SD, max, min), descriptive analysis $(\%), t$-test, analysis of variance test, correlation analysis and regression analysis.

Findings - The results demonstrate that the university teachers had experienced more work-family conflict (WFC) on job satisfaction and family-work conflict (FWC) on job and life satisfaction than doctors and engineers; however, engineers experienced more WFC in the case of life satisfaction. The study also implied that control variables such as gender identification, reported number of children, marital status, education level and adhered religion had significant impact $(p<0.05)$ on WFC, FWC, job satisfaction and life satisfaction.

Originality/value - This study will provide insight into the effects of spouse, supervisor and number of children on both job and life satisfaction.
\end{abstract}

Keywords Work-family conflict (WFC), Family-work conflict (FWC), Job satisfaction (JS), Quantitative analysis, Bangladesh

Paper type Research paper

\footnotetext{
(C) Tazrin Jahan Priyanka, Momotaj Akter Mily, Md. Asadujjaman, Mohammad Arani and Md. Mashum Billal. Published in PSU Research Review. Published by Emerald Publishing Limited. This article is published under the Creative Commons Attribution (CC BY 4.0) licence. Anyone may reproduce, distribute, translate and create derivative works of this article (for both commercial and non-commercial purposes), subject to full attribution to the original publication and authors. The full terms of this licence may be seen at http://creativecommons.org/licences/by/4.0/legalcode.

Funding: This research received no specific grant from any funding agency in the public, commercial or not-for-profit sectors.

Code availability: The commercially available SPSS Statistical Software is employed.

Conflict of interest: The authors declare that they have no conflict of interest.

Availability of data and material: The dataset and questionnaires are summarized in form of statistical analysis tables (Table 1 to Table 16).
}

Impacts of work-family role conflict

Received 18 October 2021 Revised 1 January 2022 Accepted 8 January 2022 


\section{Introduction}

Work-family conflict (WFC) is becoming an appealing concept day by day since personal and professional lives affect each other. The WFC occurs when there are incompatible demands between the work and family roles of an individual that makes participation in both roles difficult (Greenhaus and Beutell, 1985). Role conflict between work and family is important for organizations and individuals since it is linked to negative consequences (Akkas et al., 2015). Role conflict between work and family is associated with increased occupational burnout and job stress and decreased health, organizational commitment and job performance (Amstad et al., 2011). Role conflict between work and family is bi-directional, which are WFC and family-work conflict (FWC). The WFC occurs when commitments and interests at work interfere with family life, like irregular or inflexible working hours, work overload, stress, interpersonal conflict at work, unsupportive supervisor or organization (Karatepe and Kilic, 2007; Asiedu et al., 2018; Unruh et al., 2016). The FWC occurs when commitments and interests in the family interfere with work-life, like primary responsibilities for children, elder care responsibilities, interpersonal conflict within the family unit and unsupportive family members.

Job satisfaction can be defined as "a pleasurable or positive emotional state resulting from the appraisal of one's job or job experiences” (Locke, 1976). Simply it can be defined how content an individual is with his or her job. A more recent definition of the concept of job satisfaction is from Hulin and Judge (2003), who noted that job satisfaction includes multidimensional psychological responses to an individual's job and those personal responses have cognitive (evaluative), affective (or emotional) and behavioral components. On the other hand, life satisfaction is an overall assessment of feelings and attitudes about one's life at a particular point in time ranging from negative to positive (Diener et al., 1985). Life satisfaction is an employee's overall well-being resulting from their evaluation of his or her life in general (Karatepe and Baddar, 2006). The three major professions in Bangladesh doctors, engineering and university faculties - are selected to conduct the current research. With the increasing number of doctors, engineers and university faculties, it is important to know their present condition of family and work life. This study examined the impacts of WFC and FWC on life and job satisfaction among doctors, engineers and university faculties.

\section{Literature review}

Work and family are integrated important domains in social and psychological studies. Personal life and working life are the two elements affecting one another. WFC occurs when work role activities impede the performance of family responsibilities, for instance, long-hours paid work hinders duties at home. FWC occurs when family role responsibilities prevent delivering an acceptable performance level at work, for instance, a child's illness engages parents' minds resulting in lower professional concentration and performance level (Michel et al., 2011). Different studies have been conducted on WFC and FWC which indicates the strong relationship between family and work and fragile balance between them (Namasivayam and Mount, 2016; Mary and Ramesh, 2020). Zhao et al. (2011) have conducted a study on hotel sales managers in the Pearl River Delta of China and the study exhibited that especially FWC had direct and indirect impacts on life and job satisfaction. It was found that in Chinese hotels the employees who had good social status sacrificed their family to keep their job.

A study among teachers of primary and secondary education levels showed that mentors are experiencing more WFC than FWC, additionally, WFC is greater among female teachers than that of males (Erdamar and Demirel, 2014; Aycan and Eskin, 2005). Karatepe and Karadas (2014) conducted a study on full-time employees of four- and five-star international hotels in Romania and the study revealed that employees neglected their family life and the tendency of leaving their jobs increased concerning WFC. Therefore, it was found that WFC 
is more problematic than FWC. Should people have a high level of WFC, cognitive-behavioral interventions that are of assistance? It was also found that the dysfunctional cognitions between FWC and WFC negatively influenced life satisfaction (Turliuc and Buliga, 2014; Liang, 2014). In the case of employees of Greek banks and credit institutions, WFC directly affected the promotion opportunities and as employees lost their freedom, therefore they experienced high independency in the workplace (Belias et al., 2015).

Boyar and Mosley (2007) described the impact of WFC and work-family facilitation on work and family outcomes. It was also investigated that core self-evaluation (CSE) at relationship levels of 124 employees at a retirement facility/nursing home in the southern US was negatively related to work interfering with family and family interfering with work. It, however, was not related to work-to-family facilitation or family-to-work facilitation. A survey was conducted among the managers of five western countries. The participants were managers of diverse industrial organizations. A theoretical model was established of employees' perceptions of their work environment and family supportiveness to four different dimensions of WFC, job satisfaction, family satisfaction and life satisfaction (Lapierre et al., 2008). It was found that work schedule flexibility was strongly related to work responsibilities conflicting family responsibilities than the other way around.

Day-to-day variations in workload influenced life satisfaction by creating WFC, as well as the role supportive supervisor's play in influencing these daily relationships. In an experiment, 135 employees responded to two daily surveys for five days and a one-time poststudy survey with a total of 810 surveys (Goh et al., 2015). By hierarchical linear model, it was showed that employee's daily workload positively predicted daily WFC which negatively predicted daily life satisfaction indicating workload had an indirect impact on well-being evaluations via spillover effects into the home domain. On the other hand, the workload did not have a direct effect on life satisfaction.

An experiment was made in China and data were collected from 121 sales managers from 26 hotels in China (Qu and Zhao, 2012). It was investigated that when work-interfering-family (WIF) and family-interfering-work (FIW) are low, life satisfaction positively influenced job satisfaction and when work and family demands did not interfere with each other, employees who had higher life well-being, feel higher job satisfaction too. In the case of hotel employees in South India, it was observed that after controlling for the effects of age, gender, dependents, marital status and education work interfacing family had a negative association with job satisfaction but the effect was not statistically significant (Namasivayam and Zhao, 2007). It was also investigated that normative commitment and calculative commitment moderated the effects of FIW and WIF on job satisfaction. No significant relationships were evident for these components for either FIW or WIF. Cooklin et al. (2015) studied the psychological distress of working fathers. The data were collected from the Longitudinal Study of Australian Children (LSAC), a nationally representative cohort study of Australian children and their families. It was verified that several jobs and family characteristics such as long working hours, long shifts and inflexible working hours were associated with higher WFC and psychological distress, over and above demographic confounders which reduced fathers' capacities to care for their infants and support their partners. It was also found that fathers with more children experience more WFC and the quality of the intimate partner relationship, and partner's mental health status was also related to father's WFC and enrichment, and ultimately, their mental health (Allard et al., 2011).

In public health care service in Malaysia, in the case of married female nurses, a positive strong relationship between self-esteem and satisfaction outcome was observed which indicated the self-esteem that directly influenced satisfaction outcomes such as wellbeing, family and job (Rashid et al., 2012). It was revealed that there was a negative weak relationship between work/ family conflict and satisfaction outcomes which implies that the employee experienced higher conflict concerning work and family domain and they experienced lower satisfaction toward Impacts of
work-family
role conflict 
well-being, family and job. The study revealed a negative relationship between self-esteem and WFC among employees facing daily routines and the higher the self-esteem of an individual, the higher is the ability of the person to cope with the conflicting demands of work and family roles. Hashim et al. (2012) studied the WFC and job satisfaction of 90 married female teachers at selected primary and private schools in Klang Valley, Malaysia. It showed that married working women experienced more WFC.

By reviewing the previous literature, it is clear that all the papers considered only WFC on job satisfaction or life satisfaction. This study aimed at examining the relations and impacts of WFC and FWC on job satisfaction and life satisfaction for doctors, engineers and university faculties. Moreover, this study considers different variables, gender, age, institution type, number of children, education and marital status to investigate the comparative impacts of WFC and FWC on job satisfaction and life satisfaction of these three professions.

\section{Methodology \\ Procedure}

Participants in the present study were doctors, engineers and university faculties. Primary data were collected by face-to-face interviews since it provided us more reliable information compared to other methods which gave us the chance to clarify the primary goal of the research to the respondents. Initially, the authors took appointments from doctors, engineers and university faculties to introduce the objectives of the study. The data from university faculties were collected from public and private universities in Bangladesh. Hereafter, the data from doctors and engineers were collected from public and private institutes and hospitals from Dhaka, Rangpur, Pabna, Rajshahi and Khulna in Bangladesh. Due to the availability of samples, we collected data from the most popular educational institutions, hospitals and workplaces in Bangladesh. Afterward, a total of 180 interviewees from 60 engineers (39 males and 21 females), 60 doctors ( 31 males and 29 females) and 60 university faculties (20 females and 40 males) were collected. Given the emphasis on WFC, participants were appointed to be mostly married with age between 35 and 60 years old.

\section{Control variables}

In conducting our study there were eight demographic variables. These variables were age, gender, institution type, occupation, marital status, number of children and education. All variables coded as a binary variable except age and number of children. The coded variables included gender $(1=$ male, $2=$ female), institution type $(1=$ public, $2=$ private), marital status $(1=$ married, $2=$ unmarried $)$ and education $(1=$ graduate, $2=$ post-graduate). There were a total of 31 questionnaires which were distributed among the participants. All items in this study were measured using a five-point Likert-type scale ranging from 1 (not at all) to 5 (all of the time) to respond to all survey questionnaires. The items in each question of the scales were summed. Each question summed value represented job satisfaction and life satisfaction regarding WFC and FWC. High values represented a lower level of satisfaction and low values represented a higher level of satisfaction.

\section{Data analysis}

Statistical packages are the most consistent instruments for comprehensively analyzing a large set of data (Houtman et al., 2019). Therefore, data were analyzed through the help of "Statistical Package for Social Sciences" (SPSS) and MS Excel 2013 software. Statistical analysis of questionnaires (mean, SD, max, min) was conducted to measure the impacts of WFC and FWC on job and life satisfaction. Descriptive statistics performed for summarizing the sample measures. $T$-test and analysis of variance (ANOVA) were employed to analyze the effect of control variables on individuals. Correlation analysis was conducted for examining 
relationships among control variables. At last, linear regression was utilized to test the relationship between job satisfaction and life satisfaction.

\section{Results}

\section{Statistical analysis of questionnaires}

Tables 1-4 represent the statistical mean, standard deviation, maximum and minimum values of questionnaires of job satisfaction and life satisfaction with respect to WFC and FWC. These statistical values represent the impacts of WFC and FWC on job satisfaction and life satisfaction of doctors, engineers and university faculties.

In Table 1, it shows that the mean value of job satisfaction levels to WFC for doctors, engineers, and university faculties were $16.38,17.49$ and 21.41 , respectively. Considering the highest possible score 100, the satisfaction levels of doctors, engineers and university faculties were $54.6 \%, 57.3 \%$ and $71.37 \%$, respectively. According to the results, university faculties experienced more WFC than doctors and engineers; additionally, their job satisfaction level concerning WFC was less than doctors and engineers. On the contrary, the impacts of WFC were less for doctors in case of job satisfaction. Table 2 represents job satisfaction with respect to FWC. The mean scores of impacts of FWC on job satisfaction for doctors, engineers and university faculties were 30.57, 33.79 and 31.97, respectively; additionally, percentages of the satisfaction levels were $67.9 \%, 75.09 \%$ and $71.04 \%$, respectively. The result demonstrates that engineers experienced more $\mathrm{FWC}$ and their job satisfaction level concerning FWC was less than doctors and university faculties. However, the impacts of FWC were less for doctors. Table 3 exhibits the impacts of WFC on life satisfaction. The mean life satisfaction scores of doctors, engineers and university faculties were 29.23, 28.67 and 30.20, respectively. The percentages of satisfaction levels of doctors, engineers and university faculties were $64.95 \%, 63.71 \%$ and $67.11 \%$, respectively. The result indicates that university faculties experienced more WFC and their life satisfaction level concerning WFC was less than doctors and engineers. In contrast, the impacts of WFC on life satisfaction were less for engineers. Table 4 exhibits the impacts of FWC on life satisfaction. The mean life satisfaction scores of doctors, engineers, and university faculties were 24.97 , 23.02 and 25.43 , respectively. The percentages of satisfaction levels were $71.34 \%, 65.77 \%$ and $72.66 \%$ by considering the highest satisfaction score of 100 . According to the results, university faculties experienced more FWC and there was less life satisfaction concerning FWC than doctors and engineers. However, engineers experienced less FWC, and their satisfaction level was higher.

\section{Descriptive statistics}

Descriptive statistics of questionnaires about job and life satisfaction concerning WFC and FWC are shown in Tables 5-8. These statistics values represent the level of life satisfaction and job satisfaction. Table 5 represents descriptive statistics of the impacts of WFC on job satisfaction. The questionnaire presented in Table 5 is corresponding with Table 1 . These statistical values represent the respondent rate for WFC in case of job satisfaction. According to results, $36.67 \%$ of doctors selected often, $33.33 \%$ occasionally and $25 \%$ all of the time that their working hours made it difficult to fulfill family responsibilities. A total of $40 \%$ of engineers answered often and $38.33 \%$ occasionally that their working hours made it difficult to fulfill family responsibilities and $41.67 \%$ of university faculties responded rarely.

A total of $41.67 \%$ of doctors and $45 \%$ of engineers responded occasionally that they did not fulfill family responsibilities even if their family members were ill and $55 \%$ of university faculties responded rarely. $35 \%$ of doctors said that often they missed family program due to work. $40 \%$ of engineers answered often and $40 \%$ of engineers said occasionally that they
Impacts of work-family role conflict

$\longrightarrow$


PRR

Table 1.

Statistical analysis of questionnaires of job satisfaction with respect to WFC

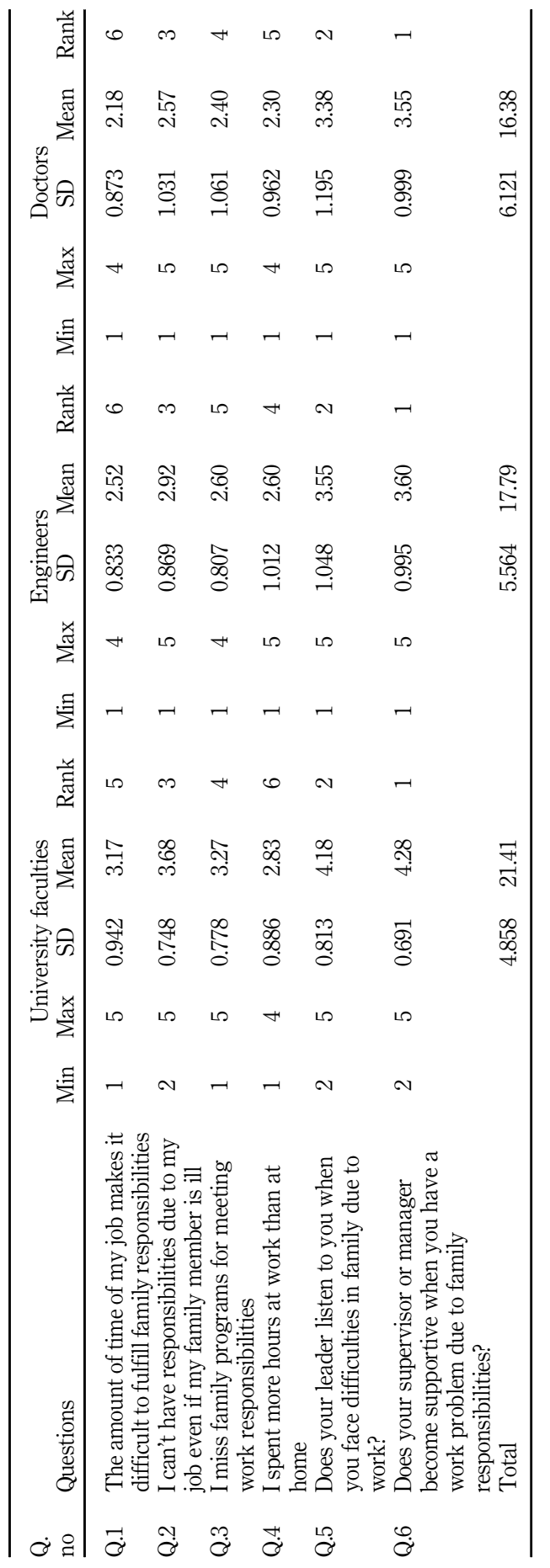




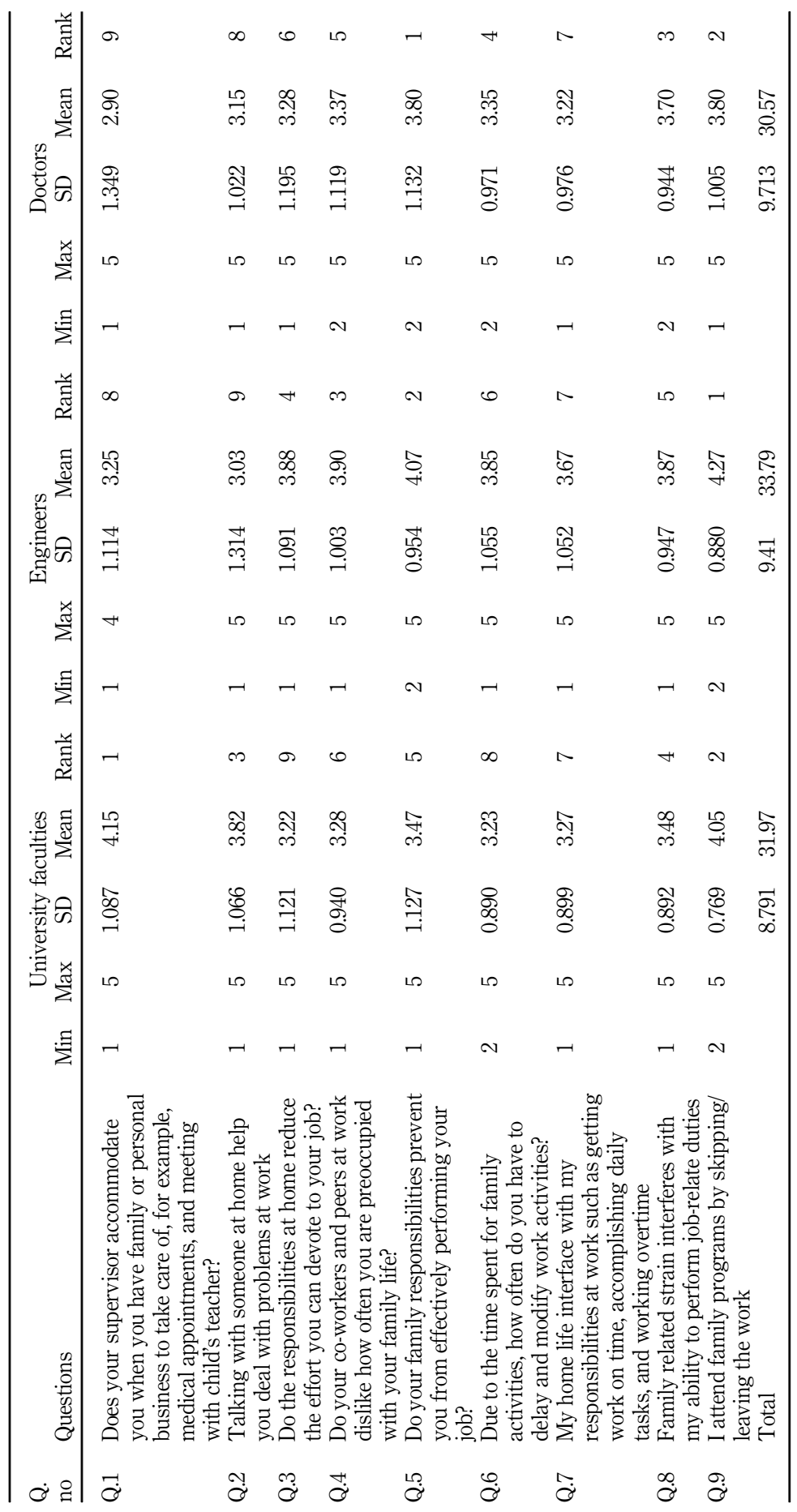

Impacts of work-family role conflict

Table 2 Statistical analysis of questionnaires of job satisfaction with respect to FWC 
PRR

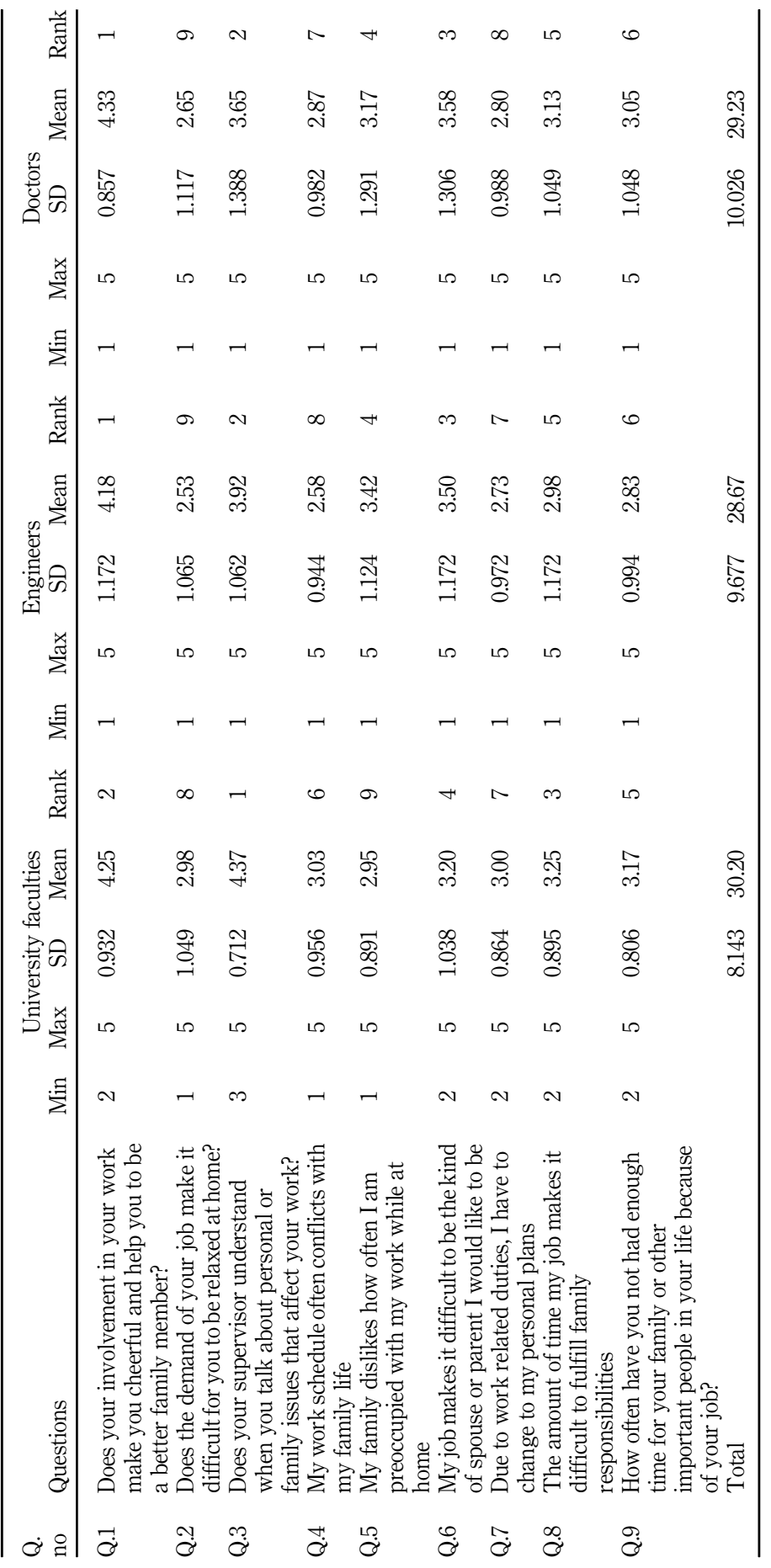

Table 3.

Statistical analysis of questionnaires of life satisfaction with respect to WFC 


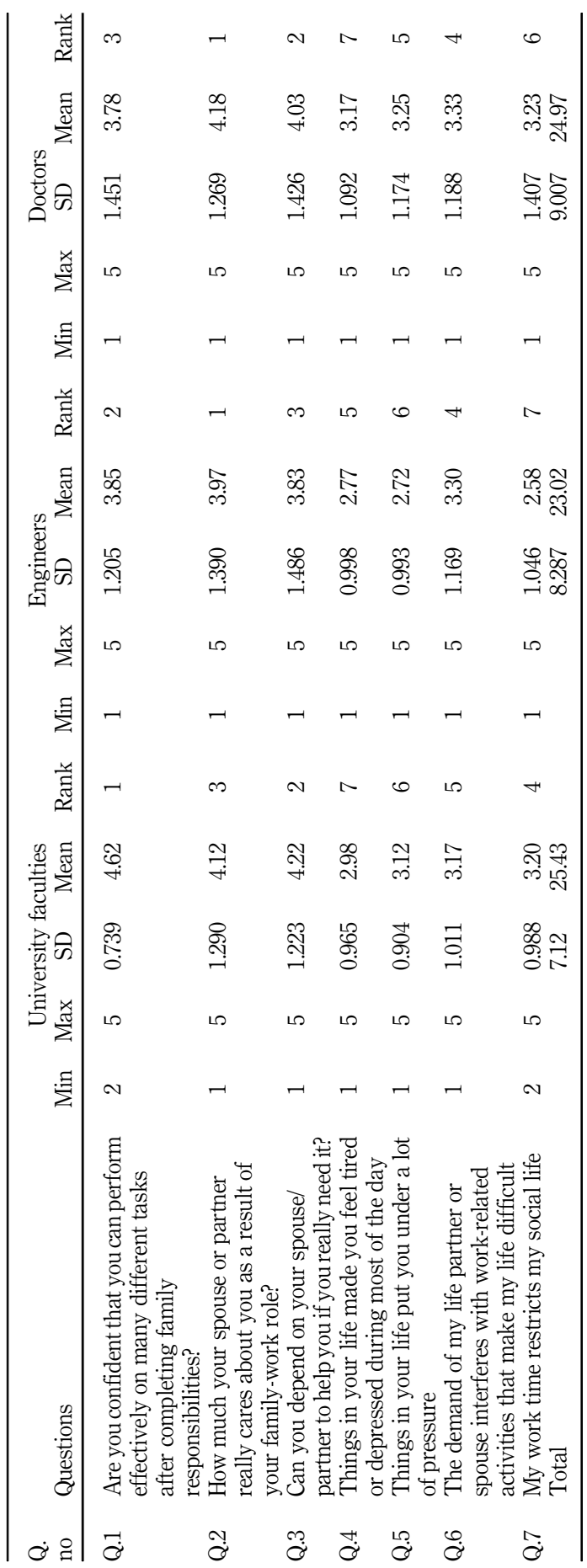

Impacts of work-family role conflict 


\section{PRR}

\begin{tabular}{lcccccc}
\hline $\begin{array}{l}\text { Satisfaction level (\%) } \\
\text { Questions no }\end{array}$ & Q.1 & Q.2 & Q.3 & Q.4 & Q.5 & Q.6 \\
\hline $\begin{array}{l}\text { Doctors } \\
\text { All of the time }\end{array}$ & 25 & 18.33 & 21.67 & 23.33 & 23.33 & 18.33 \\
Often & 36.67 & 25 & 35 & 35 & 21.6 & 35 \\
Occasionally & 33.33 & 41.67 & 28.33 & 30 & 30 & 31.67 \\
Rarely & 5 & 11.67 & 11.67 & 11.6 & 20 & 13.33 \\
Not at all & 0 & 3.33 & 3.3 & 0 & 5 & 1.67 \\
Engineers & & & & & & \\
All of the time & 10 & 1.67 & 6.67 & 16.67 & 21.67 & 20 \\
Often & 40 & 31.67 & 40 & 26.67 & 30 & 35 \\
Occasionally & 38.33 & 45 & 40 & 38.33 & 31.67 & 31.67 \\
Rarely & 11.67 & 16.67 & 13.33 & 16.67 & 15 & 11.67 \\
Not at all & 0 & 5 & 0 & 1.67 & 1.67 & 1.6 \\
University faculties & & & & & & \\
All of the time & 1.67 & 0 & 1.67 & 8.33 & 38.33 & 40 \\
Often & 28.33 & 6.67 & 11.67 & 23.33 & 46.67 & 50 \\
Occasionally & 25 & 28.33 & 48.33 & 45 & 10 & 8.33 \\
Rarely & 41.67 & 55 & 35 & 23.33 & 5 & 1.67 \\
Not at all & 3.33 & 10 & 3.33 & 0 & 0 & 0 \\
\hline
\end{tabular}

\begin{tabular}{lccccccccc}
\hline $\begin{array}{l}\text { Satisfaction level \% } \\
\text { Questions no }\end{array}$ & Q.1 & Q.2 & Q.3 & Q.4 & Q.5 & Q.6 & Q.7 & Q.8 & Q.9 \\
\hline $\begin{array}{l}\text { Doctors } \\
\text { All of the time }\end{array}$ & 16.67 & 8.33 & 1.67 & 0 & 0 & 0 & 1.67 & 0 & 1.67 \\
Often & 15 & 30 & 30 & 28.33 & 16.67 & 21.67 & 21.67 & 11.67 & 5 \\
Occasionally & 30 & 35 & 31.67 & 28.33 & 25 & 35 & 41.67 & 28.33 & 36.67 \\
Rarely & 18.33 & 21.67 & 11.67 & 21.67 & 20 & 30 & 23.33 & 38.33 & 25 \\
Not at all & 20 & 5 & 25 & 21.67 & 38.33 & 13.33 & 11.67 & 21.67 & 31.67 \\
Engineers & & & & & & & & & \\
All of the time & 16.67 & 16.67 & 3.33 & 1.67 & 0 & 3.33 & 1.67 & 1.67 & 0 \\
Often & 23.33 & 23.33 & 6.67 & 6.67 & 6.67 & 3.33 & 11.67 & 6.67 & 3.33 \\
Occasionally & 31.67 & 20 & 25 & 25 & 21.67 & 33.33 & 31.67 & 21.67 & 18.33 \\
Rarely & 25 & 26.67 & 28.33 & 33.33 & 30 & 25 & 28.33 & 43.33 & 26.67 \\
Not at all & 3.33 & 13.33 & 36.67 & 33.33 & 41.67 & 35 & 26.67 & 26.67 & 51.67 \\
University faculties & & & & & & & & & \\
All of the time & 51.67 & 31.67 & 5 & 1.67 & 3.33 & 0 & 5 & 1.67 & 0 \\
Often & 21.67 & 31.67 & 21.67 & 20 & 18.33 & 26.67 & 13.33 & 13.33 & 1.67 \\
Occasionally & 21.67 & 26.67 & 36.67 & 35 & 28.33 & 26.67 & 33.33 & 28.33 & 21.67 \\
Rarely & 0 & 6.67 & 20 & 35 & 28.33 & 43.33 & 46.67 & 48.33 & 46.67 \\
Not at all & 5 & 3.33 & 16.67 & 8.33 & 21.67 & 3.33 & 1.67 & 8.33 & 30 \\
\hline
\end{tabular}

missed family programs due to work. A total of $48.33 \%$ of university faculties answered occasionally and $35 \%$ said often regarding the same question; $46.67 \%$ of university faculties responded often and $38.33 \%$ of all the time that their supervisors listened and understood their problems, and $31.67 \%$ of engineers and $30 \%$ of doctors answered occasionally that their supervisors listened and understood their problems. 


\begin{tabular}{|c|c|c|c|c|c|c|c|c|c|c|}
\hline $\begin{array}{l}\text { Satisfaction level } \\
\text { Questions no }\end{array}$ & $\%$ & Q.2 & Q.3 & Q.4 & Q.5 & Q.6 & Q.7 & Q.8 & Q.9 & $\begin{array}{l}\text { Impacts of } \\
\text { work-family }\end{array}$ \\
\hline \multicolumn{11}{|l|}{ Doctors } \\
\hline All of the time & 51.67 & 16.67 & 38.33 & 11.67 & 11.67 & 6.67 & 11.67 & 5 & 6.67 & \\
\hline Often & 35 & 30 & 21.67 & 20 & 18.33 & 16.67 & 23.33 & 21.67 & 23.33 & \\
\hline Occasionally & 10 & 30 & 18.33 & 38.33 & 33.33 & 23.33 & 40 & 40 & 36.67 & \\
\hline Rarely & 1.67 & 18.33 & 10 & 30 & 15 & 18.33 & 23.33 & 21.67 & 25 & \\
\hline Not at all & 1.67 & 5 & 11.67 & 0 & 21.67 & 35 & 1.67 & 11.67 & 8.33 & \\
\hline \multicolumn{11}{|l|}{ Engineers } \\
\hline All of the time & 55 & 20 & 38.33 & 15 & 5 & 3.33 & 6.67 & 8.33 & 6.67 & \\
\hline Often & 25 & 25 & 26.67 & 26.67 & 15 & 16.67 & 38.33 & 30 & 33.33 & \\
\hline Occasionally & 10 & 41.67 & 25 & 45 & 33.33 & 35 & 35 & 30 & 35 & \\
\hline Rarely & 3.33 & 8.33 & 8.33 & 11.67 & 26.67 & 16.67 & 15 & 18.33 & 20 & \\
\hline Not at all & 6.67 & 5 & 1.67 & 1.67 & 20 & 28.33 & 5 & 13.33 & 5 & \\
\hline \multicolumn{11}{|l|}{ University faculties } \\
\hline All of the time & 51.67 & 1.67 & 50 & 1.67 & 1.67 & 0 & 0 & 0 & 0 & \\
\hline Often & 28.33 & 38.33 & 36.67 & 30 & 28.33 & 31.67 & 33.33 & 20 & 20 & Table 7. \\
\hline Occasionally & 13.33 & 31.67 & 13.33 & 40 & 31.67 & 30 & 36.67 & 45 & 48.33 & Descriptive statistics of \\
\hline Rarely & 6.67 & 16.67 & 0 & 20 & 10 & 25 & 26.67 & 25 & 26.67 & life satisfaction with \\
\hline Not at all & 0 & 11.67 & 0 & 8.33 & 8.33 & 13.33 & 3.33 & 10 & 5 & respect to $\mathrm{WFC}$ \\
\hline
\end{tabular}

\begin{tabular}{|c|c|c|c|c|c|c|c|c|}
\hline $\begin{array}{l}\text { Satisfaction level \% } \\
\text { Questions no }\end{array}$ & Q.1 & Q.2 & Q.3 & Q.4 & Q.5 & Q.6 & Q.7 & \\
\hline \multicolumn{9}{|l|}{ Doctors } \\
\hline All of the time & 48.33 & 58.33 & 58.33 & 5 & 8.33 & 8.33 & 15 & \\
\hline Often & 16.67 & 23.33 & 16.67 & 25 & 20 & 15 & 23.33 & \\
\hline Occasionally & 11.67 & 6.67 & 8.33 & 30 & 23.33 & 30 & 5 & \\
\hline Rarely & 11.67 & 1.67 & 3.33 & 28.33 & 35 & 28.33 & 36.67 & \\
\hline Not at all & 11.67 & 10 & 13.33 & 11.67 & 13.33 & 18.33 & 20 & \\
\hline \multicolumn{9}{|l|}{ Engineers } \\
\hline All of the time & 35 & 50 & 46.67 & 11.67 & 13.33 & 6.67 & 16.67 & \\
\hline Often & 40 & 26.67 & 26.67 & 26.67 & 25 & 16.67 & 30 & \\
\hline Occasionally & 5 & 6.67 & 8.33 & 36.67 & 40 & 36.67 & 35 & \\
\hline Rarely & 15 & 3.33 & 0 & 23.33 & 20 & 20 & 15 & \\
\hline Not at all & 5 & 13.33 & 18.33 & 1.67 & 1.67 & 20 & 3.33 & \\
\hline \multicolumn{9}{|l|}{ University faculties } \\
\hline All of the time & 75 & 58.33 & 60 & 1.67 & 1.67 & 1.67 & 0 & \\
\hline Often & 13.33 & 16.67 & 20 & 33.33 & 23.33 & 25 & 28.33 & Table 8 \\
\hline Occasionally & 10 & 11.67 & 10 & 38.33 & 43.33 & 41.67 & 35 & Descriptive statistics of \\
\hline Rarely & 1.67 & 5 & 1.67 & 18.33 & 25 & 18.33 & 25 & life satisfaction with \\
\hline Not at all & 0 & 8.33 & 8.33 & 8.33 & 6.67 & 13.33 & 11.67 & respect to FWC \\
\hline
\end{tabular}

Table 6 shows the descriptive statistics of questionnaires about the impacts of FWC on job satisfaction. The questionnaire presented in Table 6 is corresponding with Table 2. The questionnaire is the same as Table 2 . According to the results, $51.67 \%$ of university faculties said all of the time, $30.67 \%$ of doctors and $30 \%$ of engineers said occasionally that their supervisor helped them to fulfill their family responsibilities. In total, $31.67 \%$ of doctors and $36.67 \%$ of university faculties answered occasionally that their family responsibilities reduced their efforts 
while working, whereas, $25 \%$ of doctors and $36.67 \%$ of engineers said not at all that their family responsibilities reduced their efforts while working. A total of $36.67 \%$ of doctors answered occasionally and $51.67 \%$ of engineers responded not at all that they skipped work dues in favor of family events; $46.67 \%$ of university faculties answered rarely and $30 \%$, not at all that they skipped work dues in favor of family events; $38.33 \%$ of doctors and $41.67 \%$ of engineers replied not at all that their family responsibilities prevented them from effectively performing in their jobs, and $41.67 \%$ of doctors and $31.67 \%$ of engineers answered occasionally that their family lives to interfere with work their responsibilities and $46.67 \%$ of university faculties answered rarely.

Table 7 represents the descriptive statistics of questionnaires about the impacts of WFC on life satisfaction. The questionnaire presented in Table 7 is corresponding with Table 3 . According to the results, $30 \%$ of doctors, $25 \%$ of engineers and $38.33 \%$ of university faculties said often and $30 \%$ of doctors, $41.67 \%$ of engineers and $31.67 \%$ of university faculties said occasionally that working hours prevented them from relaxing at home. A total of $38.33 \%$ of doctors, $38.33 \%$ of engineers and $50 \%$ of university faculties answered that their supervisors were supportive throughout any WFC; $38.33 \%$ of doctors, $45 \%$ of engineers and $40 \%$ of university faculties responded occasionally that their work schedules conflicted with family lives; $40 \%$ of doctors and $36.67 \%$ of university faculties responded occasionally that they changed their personal plans due to work duties and $38.33 \%$ of engineers responded often; $40 \%$ of doctors, $30 \%$ of engineers and $45 \%$ of university faculties answered occasionally that their jobs made difficulties to fulfill family responsibilities; $36.67 \%$ of doctors, $33.33 \%$ of engineers and $48.33 \%$ of university faculties responded occasionally that they did not have enough time for their family.

Table 8 represents the life satisfaction level concerning FWC. The questionnaire presented in Table 8 is corresponding with Table 4 . According to the results, $48.33 \%$ of doctors and $75 \%$ of university faculties responded all of the time, $40 \%$ of engineers answered often that they could perform effectively at work after completing family responsibilities. The majority of doctors $(58.33 \%)$, engineers $(50 \%)$ and university faculties $(58.33 \%)$ responded all of the time that their spouses cared about their family-work roles. The majority of doctors (58.33\%), engineers $(46.67 \%)$ and university faculties $(60 \%)$ responded all of the time that they depended on their partners or spouses. In total, $30 \%$ of doctors, $36.67 \%$ of engineers and $41.67 \%$ of university faculties responded occasionally that their life partners' or spouses' demand interfered with work-related activities that made their lives; $35 \%$ of engineers, $35 \%$ of university faculties responded occasionally and $36.67 \%$ of doctors replied rarely that their work lives restricted their social lives.

\section{$T$-tests and ANOVA}

$T$-tests and ANOVA were conducted to analyze the effect of control variables on individuals. Tables 9-14 represent the comparison between impacts of WFC and FWC on job satisfaction and life satisfaction for doctors, engineers and university faculties. In Table 9 represents the comparison between the impacts of WFC and FWC on job satisfaction for doctors. The results revealed that for doctors, the number of children $(\phi<0.05)$ had a significant impact on WFC regarding job satisfaction. From the mean score of the number of children, it revealed that doctors with fewer children experienced more WFC and their life satisfaction was less. On the other hand, control variables did not have any significant impact on FWC regarding job satisfaction.

Table 10 represents the comparison between WFC and FWC in case of life satisfaction for the interviewed doctors. The analysis disclosed that gender $(\phi<0.05)$, marital status $(p<0.01)$, number of children $(\phi<0.001)$ and education $(\phi<0.001)$ had a significant impact on $\mathrm{WFC}$ regarding life satisfaction. According to the results, female doctors experienced more 


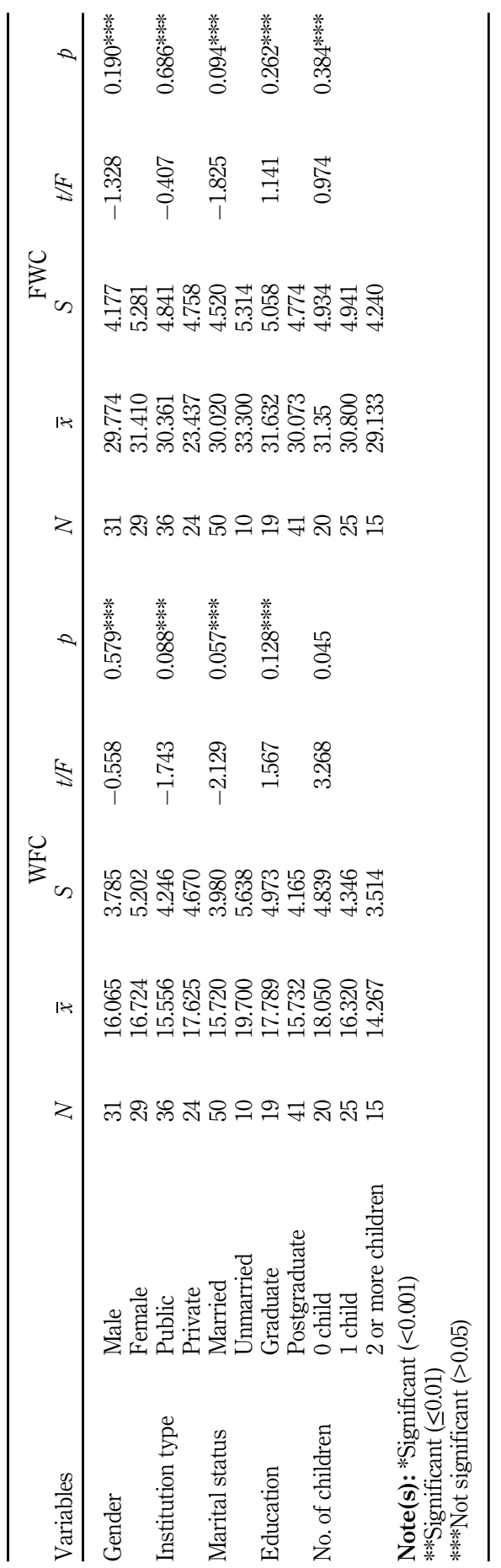

Impacts of work-family role conflict 
PRR

Table 10.

Comparison of WFC and FWC on life satisfaction for doctors

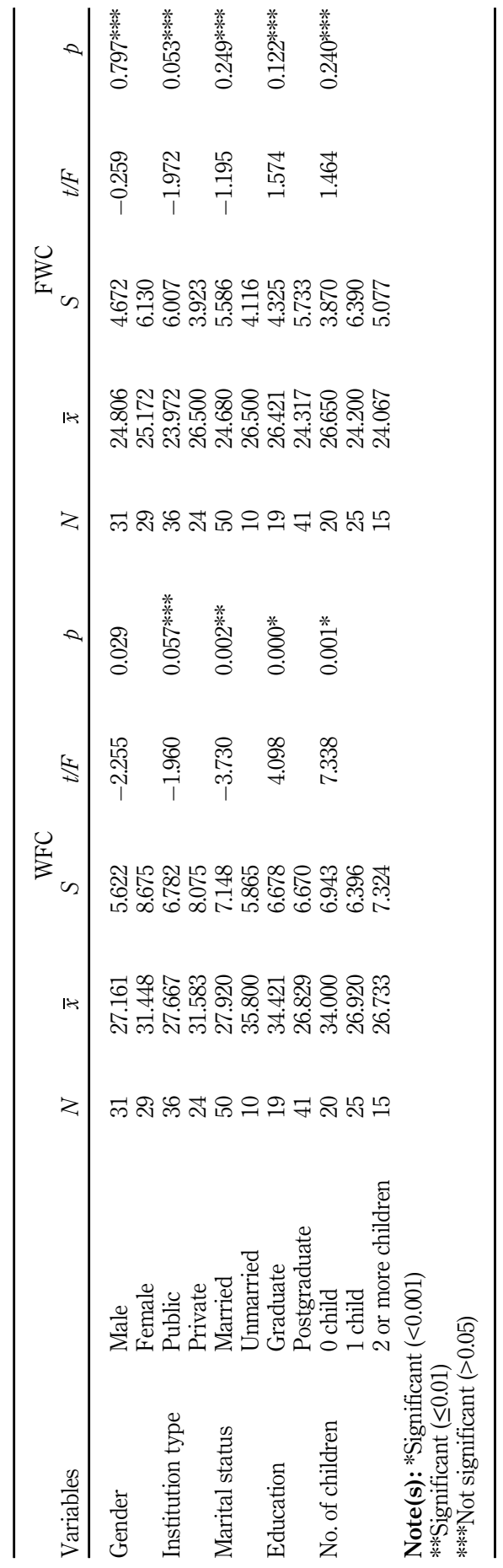




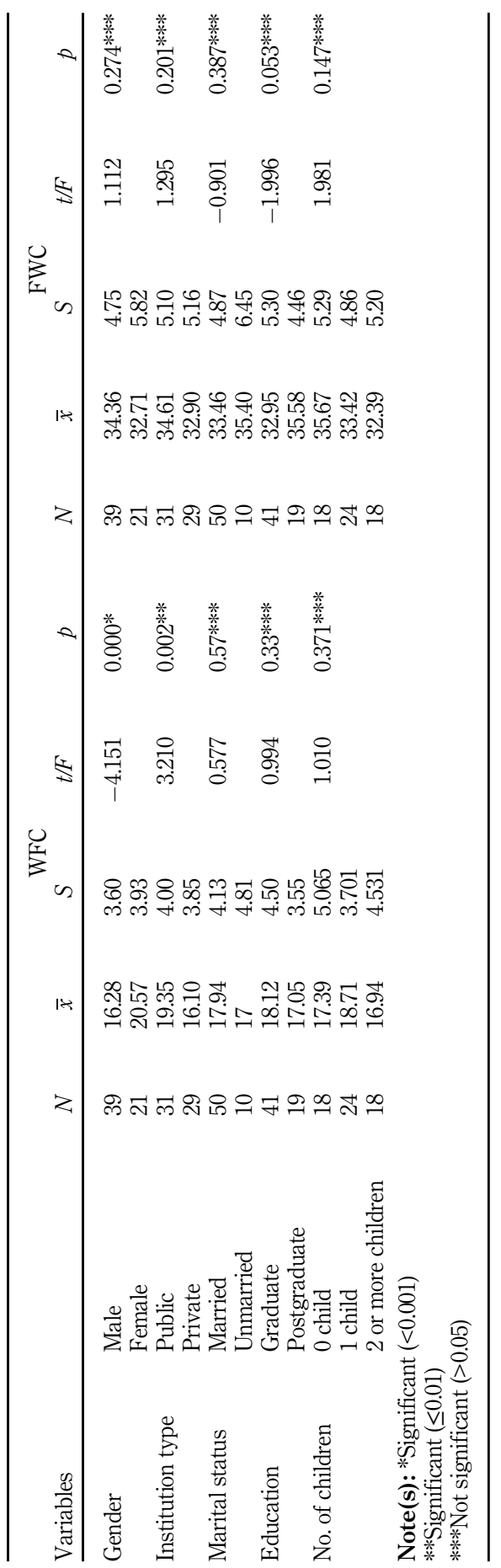

Impacts of work-family role conflict 
PRR

Table 12.

Comparison of WFC

and FWC on life

satisfaction for engineers

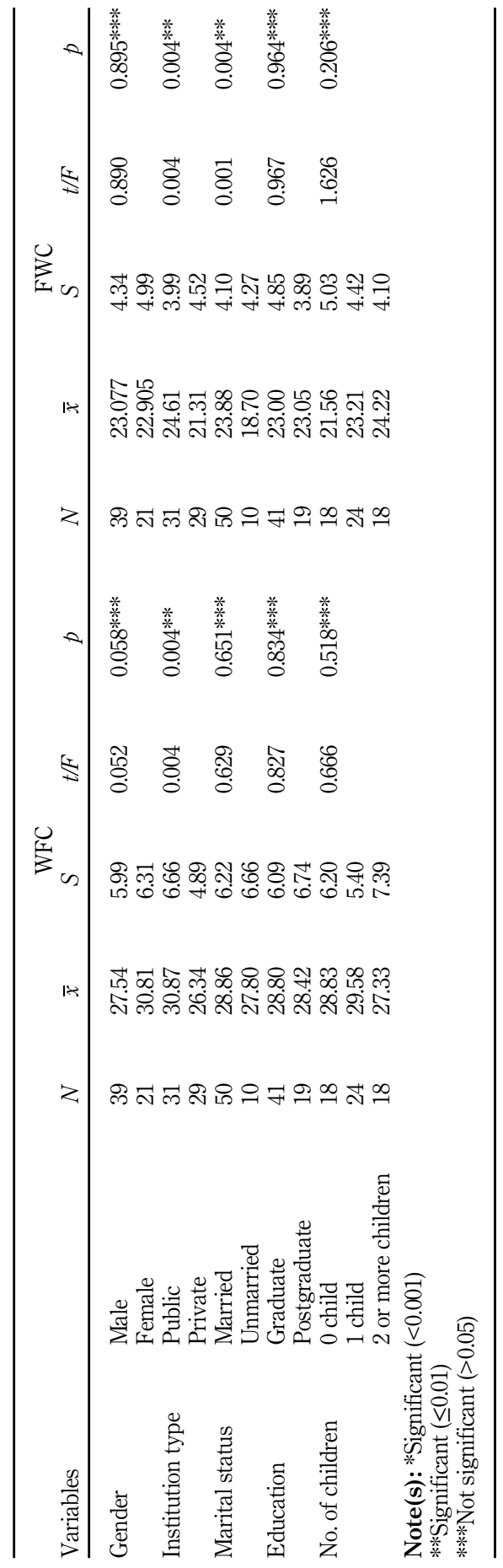




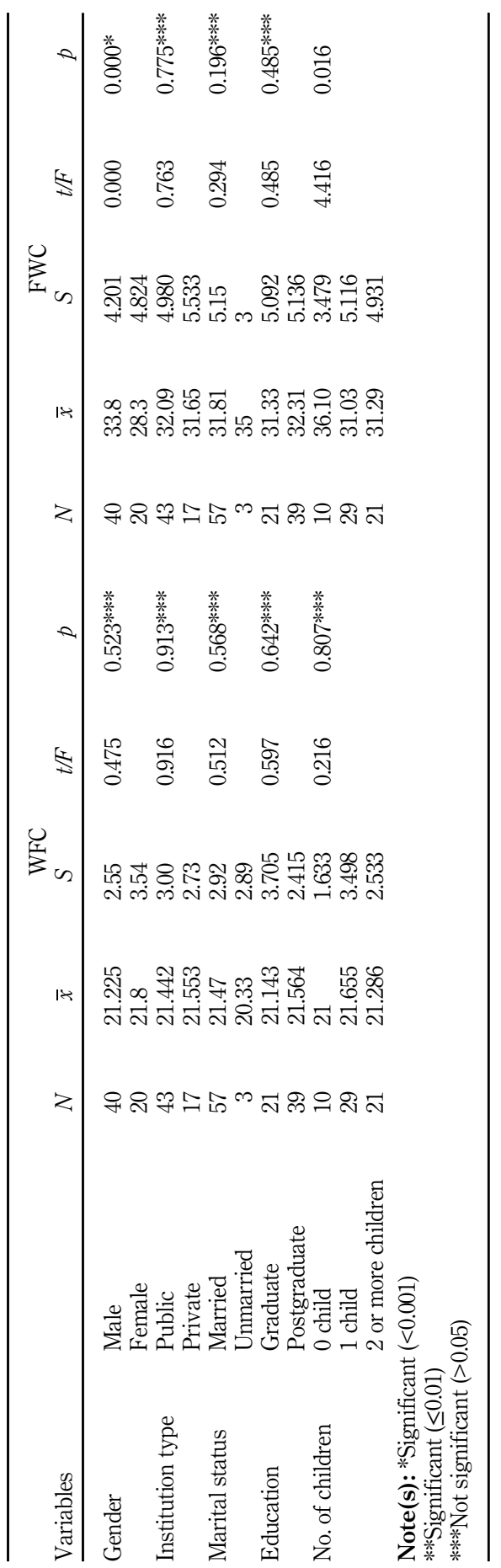

Impacts of work-family role conflict 
PRR

Table 14.

Comparison of WFC

and FWC on life

satisfaction for university faculties

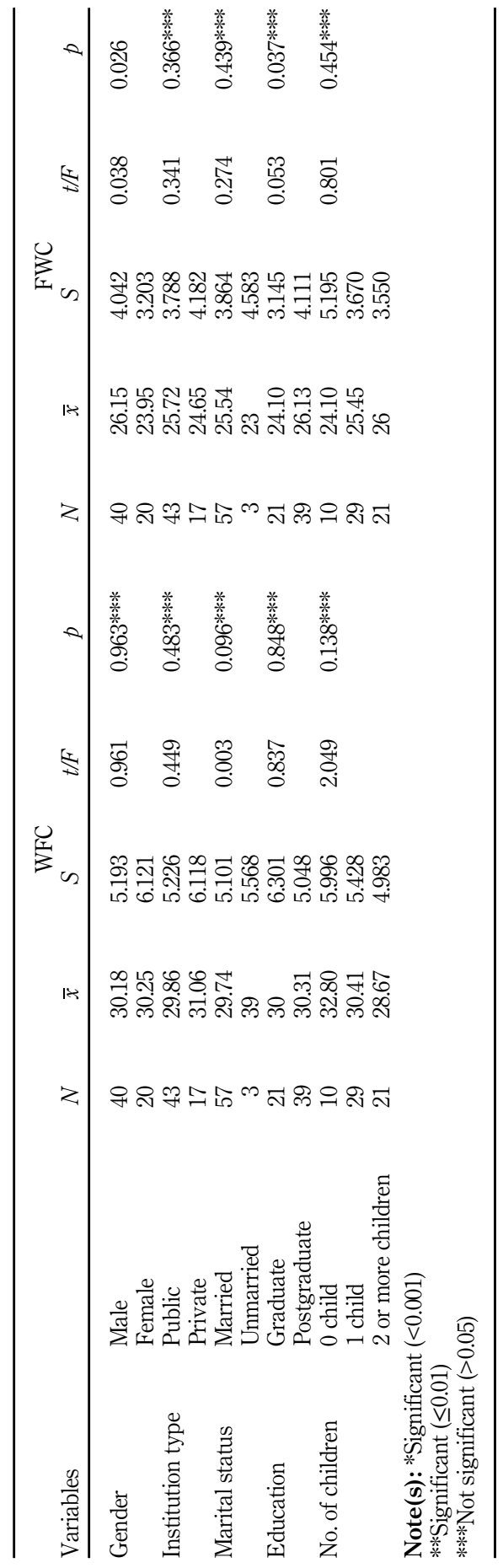


WFC than males. On the other hand, married, lower education level doctors experienced more WFC and doctors with fewer children experienced more WFC.

Table 11 represents the comparison between the impacts of WFC and FWC on job satisfaction for engineers. The analysis demonstrated that gender $(\phi<0.001)$ and institution type $(\phi<0.01)$ had significant impacts on WFC regarding job satisfaction. According to the results, female and public institute engineers experienced more WFC. Impacts of WFC mean less job satisfaction.

Table 12 represents the comparison between the impacts of WFC and FWC on life satisfaction for engineers. The result revealed that institution type $(\phi<0.01)$ had a significant impact on WFC regarding life satisfaction. Moreover, institution type $(\phi<0.01)$ and marital status $(p<0.01)$ had significant effects on $\mathrm{FWC}$ regarding life satisfaction. According to the results, married engineers working in public institutes experienced more FWC.

Table 13 exhibits the comparison between the impacts of WFC and FWC on job satisfaction for university faculties. According to the results, gender $(\phi<0.001)$ and the number of children $(\phi<0.05)$ had significant impacts on FWC regarding job satisfaction. Female university faculties with more children experienced more FWC in the case of job satisfaction.

Table 14 exhibits the comparison between the impacts of WFC and FWC on life satisfaction for university faculties. The analysis showed that gender $(\phi<0.05)$ had a significant impact on FWC regarding job satisfaction. According to the results, male university faculties experienced more FWC than females in the case of life satisfaction.

\section{Correlation analysis}

Table 15 represents the correlation analysis. For the doctors, the result disclosed that age negatively and strongly correlated $(p<0.01)$ with impacts of FWC on life satisfaction, and impacts of WFC on life satisfaction and job satisfaction. The number of children negatively correlated with impacts of WFC on life satisfaction $(\phi<0.05)$ and positively correlated with impacts of WFC on job satisfaction $(\phi<0.01)$. Impacts of WFC on life and job satisfaction positively and strongly correlated $(\phi<0.01)$ with impacts of FWC on life satisfaction and job satisfaction. Impacts of WFC on life and job satisfaction also positively correlated $(\phi<0.01)$ with each other.

For the engineers, the results demonstrate that the age negatively and strongly correlated with the number of children and positively correlated with the impacts of FWC on life satisfaction $(\phi<0.01)$. Impacts of WFC on life and job satisfaction positively and strongly correlated $(p<0.01)$ with impacts of FWC on life and job satisfaction. Impacts of WFC on life and job satisfaction also positively correlated $(\phi<0.01)$ with each other. For the university faculties, the age positively and strongly correlated with the impacts of FWC on life satisfaction $(\phi<0.05)$. The number of children positively and strongly correlated with the impacts of FWC on job satisfaction $(\phi<0.05)$. Impacts of FWC on job satisfaction positively and strongly correlated $(\phi<0.05)$ with impacts of FWC on life satisfaction and impacts of WFC on life satisfaction.

\section{Regression analysis}

Table 16 represents the regression analysis for doctors, engineers and university faculties, where life satisfaction is a dependent variable, and job satisfaction is an independent variable. In all the cases, doctors, engineers and university faculties, the estimation of life satisfaction from job satisfaction was statistically significant $(p<0.05)$. The result shows that the values of the coefficient of determinations $\left(R^{2}\right)$ for doctors, engineers and university faculties are $0.254,0.313$ and 0.173 , respectively. Furthermore, the results also show that the values of
Impacts of work-family role conflict

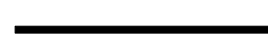


studies examining the relationship of WFC on job and life satisfaction: a case of hotel sales managers (Zhao et al., 2011), the study found that especially FWC has direct and indirect impacts on job and life satisfaction. The current study revealed that gender, institute type, marital status, education and number of children had significant impacts $(\phi<0.05)$ on job and life satisfaction of doctors, engineers and university faculties. In contrast to our study (Namasivayam and Zhao, 2007), stated that age, gender, marital status and education work interfering with family had a negative association with job satisfaction but the effect was not statistically significant.

The current study examined that job satisfaction had a positive effect on life satisfaction. This finding was also compatible with the findings from the study conducted by Qu and Zhao (2012). The current study also found that married and lower educated level doctors experienced more WFC. On the other hand, married and public institute engineers experienced more FWC, and their life satisfaction levels were lower. The study implied that female doctors and female engineers experienced more WFC than males; additionally, female university faculties experienced more FWC than males. These findings were consistent with the previous study (Erdamar and Demirel, 2014), the study revealed that university faculties experienced more WFC than FWC; however, WFC is greater among female lecturers than males. These findings are also consistent with a previous study by Hashim et al. (2012), the study found that married working women experienced more WFC.

In the current study, university faculties with more children experienced more FWC in case of job satisfaction and doctors with fewer children experienced more WFC in case of life satisfaction. Cooklin et al. (2015) found that fathers with more children experienced more WFC and the quality of the intimate partner relationship, and the partner's mental health status was also related to father's WFC, life enrichment, and ultimately, their mental health. Family domains and work domains are interrelated and undoubtedly affect each other. Family problems may cause work problems or the other way around. Family problems create life dissatisfaction and job dissatisfaction. From our perspective, a supportive supervisor, spouse, partner, children and family member help to diminish WFC and FWC. On the contrary, an unsupportive supervisor, spouse, partner, children and family members increase WFC and FWC. In short, the impacts of FWC on job and life satisfaction were more than WFC in cases of doctors, engineers and university faculties.

\section{Practical implications}

The sample of current study comprises the impact of WFC and FWC of doctors, engineers and university teachers and therefore the results indicate some practical and managerial implications. It has been observed that the mental health and individuals' behavior toward work and family make a difference while influencing job and life satisfaction. The findings suggest that excellent working environment, supportive coworkers and teamwork in hospitals helps doctors to build a healthy working facility which also provides the opportunity to manage time for both work and family increasing the job and life satisfaction. In addition, the doctors who are self-motivated and dynamic are more efficient in preventing $\mathrm{WFC}$ and FWC than the other professionals.

On the other hand, WFC and FWC differ for engineers engaged in public and private jobs according to their ambitions or career goals. It has been found that the career orientated engineers are more promotion focused than the family orientated engineers. The career orientated engineers always give high priority to work with a high-level expectation of promotion and often unable to make balance between work and family role which leads to low life satisfaction. In contrast, family orientated engineers often show capability in performing task and time management skill. The results of this study provide a differentiated assessment on how professionals can manage their WFC, FWC effectively. Moreover, managers play a significant role in identifying self-regulated employees and developing polices for assisting Impacts of
work-family
role conflict 
individuals. Managers should support and encourage the career orientated employees by providing better career training increasing the job satisfaction. Establishment of childcare facilities, youth care centers and social assistance may attract family orientated female employees avoiding the negative impact of WFC and FWC.

Administrative assistance may increase for the university teachers which help to manage WFC and FWC increasing their job and life satisfaction. Family support is one of the strongest parts for the university teachers which creates a beneficial work and family interface that brings success in both domains. In brief, providing supportive supervisor, flexible working hours and changing student behavior will decrease the negative impact of WFC that will finally increase the job satisfaction of university teachers.

\section{Conclusion}

As increasing the number of doctors, engineers and university faculties, undoubtedly it is important to know their work and family life conditions and the impacts of WFC and FWC on their families and jobs. This study examined the impacts of WFC and FWC on job and life satisfaction and it revealed that job and life satisfaction levels of doctors, engineers and university faculties in a comparison-based analysis. The present study concludes that the impacts of WFC and FWC on job and life satisfaction were more for university faculties than doctors, engineers. The current study also demonstrated that gender, institution type, marital status, education and number of children had significant impacts $(p<0.05)$ on job and life satisfaction of doctors, engineers and university faculties.

After thorough consideration, it could be pointed out that university faculties experienced more WFC on job satisfaction and FWC on job and life satisfaction than doctors and engineers. On the contrary, engineers experienced more WFC in the case of life satisfaction. The overall overview of the present work and family life condition of doctors, engineers and university faculties was studied in detail. The findings will help to understand the contribution of spouse, supervisor and number of children on both job and life satisfaction.

\section{References}

Akkas, M.A., Hossain, M.I. and Rhaman, S. (2015), "Causes and consequences of work-family conflict (WFC) among the female employees in Bangladesh: an empirical study", Journal of Business and Economics, Vol. 6 No. 12, pp. 2063-2071, doi: 10.15341/jbe(2155-7950)/12.06.2015/007.

Allard, K., Haas, L. and Hwang, C.P. (2011), "Family-supportive organizational culture and fathers' experiences of work-family conflict in Sweden”, Gender, Work and Organization, Vol. 18 No. 2, pp. 141-157, doi: 10.1111/j.1468-0432.2010.00540.x.

Amstad, F.T., Meier, L.L., Fasel, U., Elfering, A. and Semmer, N.K. (2011), "A meta-analysis of workfamily conflict and various outcomes with a special emphasis on cross-domain versus matching-domain relations", Journal of Occupational Health Psychology, Vol. 16 No. 2, pp. 151-169, doi: 10.1037/a0022170.

Asiedu, E.E.A., Annor, F., Amponsah-Tawiah, K. and Dartey-Baah, K. (2018), "Juggling family and professional caring: role demands, work-family conflict and burnout among registered nurses in Ghana", Nurs Open, Vol. 5 No. 4, pp. 611-620, doi: 10.1002/nop2.178.

Aycan, Z. and Eskin, M. (2005), "Relative contributions of childcare, spousal support, and organizational support in reducing work-family conflict for men and women: the case of Turkey”, Sex Roles, Vol. 53 Nos 7-8, pp. 453-471, doi: 10.1007/s11199-005-7134-8.

Belias, D., Koustelios, A., Sdrolias, L. and Aspridis, G. (2015), "Job satisfaction, role conflict and autonomy of employees in the Greek banking organization”, Procedia - Social and Behavioral Sciences, Vol. 175, pp. 324-333, doi: 10.1016/j.sbspro.2015.01.1207. 
Boyar, S.L. and Mosley, D.C. (2007), "The relationship between core self-evaluations and work and family satisfaction: the mediating role of work-family conflict and facilitation", Journal of Vocational Behavior, Vol. 71 No. 2, pp. 265-281, doi: 10.1016/j.jvb.2007.06.001.

Cooklin, A.R., Giallo, R., Strazdins, L., Martin, A., Leach, L.S. and Nicholson, J.M. (2015), "What matters for working fathers? Job characteristics, work-family conflict and enrichment, and fathers' postpartum mental health in an Australian cohort", Social Science and Medicine, Vol. 146, pp. 214-222, doi: 10.1016/j.socscimed.2015.09.028.

Diener, E., Emmons, R.A., Larsen, R.J. and Griffin, S. (1985), "The satisfaction with life scale”, Journal of Personality Assessment, Vol. 49 No. 1, pp. 71-75, doi: 10.1207/s15327752jpa4901_13.

Erdamar, G. and Demirel, H. (2014), "Investigation of work-family, family-work conflict of the teachers", Procedia - Social and Behavioral Sciences, Vol. 116, pp. 4919-4924, doi: 10.1016/j. sbspro.2014.01.1050.

Goh, Z., Ilies, R. and Wilson, K.S. (2015), 'Supportive supervisors improve employees' daily lives: the role supervisors play in the impact of daily workload on life satisfaction via work-family conflict”, Journal of Vocational Behavior, Vol. 89, pp. 65-73, doi: 10.1016/j.jvb.2015.04.009.

Greenhaus, J.H. and Beutell, N.J. (1985), "Sources of conflict between work and family roles", Academy of Management Review, Vol. 10 No. 1, pp. 76-88, doi: 10.5465/amr.1985.4277352.

Hashim, N., Ishar, N.I.M., Rashid, W.E.W. and Masodi, M.S. (2012), "Personality traits, work-family conflict and job satisfaction: items validity using rasch measurement approach", Procedia Social and Behavioral Sciences, Vol. 65, pp. 1013-1019, doi: 10.1016/j.sbspro.2012.11.235.

Houtman, C.J., Kroesbergen, J., Baggelaar, P.K. and van Lieverloo, J.H.M. (2019), "Statistical analysis of a large set of semi-quantitative GC-MS screening data to evaluate and prioritize organic contaminants in surface and drinking water of The Netherlands", Science of the Total Environment, Vol. 697, p. 133806, doi: 10.1016/j.scitotenv.2019.133806.

Hulin, C.L. and Judge, T.A. (2003), "Job attitudes", in Borman, W.C., Ilgen, D.R., Klimoski, R.J. and Weiner, I.B. (Eds), Handbook of Psychology, 12: Industrial and Organizational Psychology, Wiley, New York, NY, pp. 255-276.

Karatepe, O.M. and Baddar, L. (2006), "An empirical study of the selected consequences of frontline employees' work-family conflict and family-work conflict", Tourism Management, Vol. 27 No. 5, pp. 1017-1028, doi: 10.1016/j.tourman.2005.10.024.

Karatepe, O.M. and Karadas, G. (2014), "The effect of psychological capital on conflicts in the workfamily interface, turnover and absence intentions", International Journal of Hospitality Management, Vol. 43, pp. 132-143, doi: 10.1016/j.jijhm.2014.09.005.

Karatepe, O.M. and Kilic, H. (2007), "Relationships of supervisor support and conflicts in the workfamily interface with the selected job outcomes of frontline employees", Tourism Management, Vol. 28 No. 1, pp. 238-252, doi: 10.1016/j.tourman.2005.12.019.

Lapierre, L.M., Spector, P.E., Allen, T.D., Poelmans, S., Cooper, C.L., O’Driscoll, M.P., Sanchez, J.I., Brough, P. and Kinnunen, U. (2008), "Family-supportive organization perceptions, multiple dimensions of work-family conflict, and employee satisfaction: a test of model across five samples", Journal of Vocational Behavior, Vol. 73 No. 1, pp. 92-106, doi: 10.1016/j.jvb.2008.02.001.

Liang, H.-L. (2014), “Testing a negative workplace event and life satisfaction in Taiwan: neuroticisms as two moderators of the mediating roles of psychological strain", Social Indicators Research, Vol. 120 No. 2, pp. 559-575, doi: 10.1007/s11205-014-0605-y.

Locke, E.A. (1976), "The nature and causes of job satisfaction”, in Dunnette, M.D. (Ed.), Handbook of Industrial and Organizational Psychology, Rand McNally, Chicago, pp. 1297-1349.

Mary, M.A.J. and Ramesh, V. (2020), "An empirical study on the effect of work/family conflict to worklife integration (WLI)", Materials Today: Proceedings, Vol. 37, doi: 10.1016/j.matpr.2020.07.721.

Michel, J.S., Kotrba, L.M., Mitchelson, J.K., Clark, M.A. and Baltes, B.B. (2011), "Antecedents of workfamily conflict: a meta-analytic review", Journal of Organizational Behavior, Vol. 32 No. 5, pp. 689-725, doi: 10.1002/job.695. 
Namasivayam, K. and Mount, D.J. (2016), "The relationship of work-family conflicts and family-work conflict to job satisfaction", Journal of Hospitality and Tourism Research, Vol. 28 No. 2, pp. 242-250, doi: 10.1177/1096348004264084.

Namasivayam, K. and Zhao, X. (2007), "An investigation of the moderating effects of organizational commitment on the relationships between work-family conflict and job satisfaction among hospitality employees in India”, Tourism Management, Vol. 28 No. 5, pp. 1212-1223, doi: 10. 1016/j.tourman.2006.09.021.

Qu, H. and Zhao, X. (2012), "Employees' work-family conflict moderating life and job satisfaction", Journal of Business Research, Vol. 65 No. 1, pp. 22-28, doi: 10.1016/j.jbusres.2011.07.010.

Rashid, W.E.W., Nordin, M.S., Omar, A. and Ismail, I. (2012), "Work/family conflict: the link between self-esteem and satisfaction outcomes", Procedia - Social and Behavioral Sciences, Vol. 65, pp. 564-569, doi: 10.1016/j.sbspro.2012.11.166.

Turliuc, M.N. and Buliga, D. (2014), "Work-family conflict and job and family satisfaction. The mediating role of cognitions”, Procedia - Social and Behavioral Sciences, Vol. 159, pp. 105-109, doi: 10.1016/j.sbspro.2014.12.338.

Unruh, L.Y., Raffenaud, A. and Fottler, M. (2016), "Work-family conflict among newly licensed registered nurses: a structural equation model of antecedents and outcomes", Journal of Healthcare Management, Vol. 61 No. 2, pp. 129-145.

Zhao, X., Qu, H. and Ghiselli, R. (2011), "Examining the relationship of work-family conflict to job and life satisfaction: a case of hotel sales managers", International Journal of Hospitality Management, Vol. 30 No. 1, pp. 46-54, doi: 10.1016/j.ijhm.2010.04.010.

\section{Corresponding author}

Mohammad Arani can be contacted at: mxarani@ualr.edu

For instructions on how to order reprints of this article, please visit our website:

www.emeraldgrouppublishing.com/licensing/reprints.htm

Or contact us for further details: permissions@emeraldinsight.com 